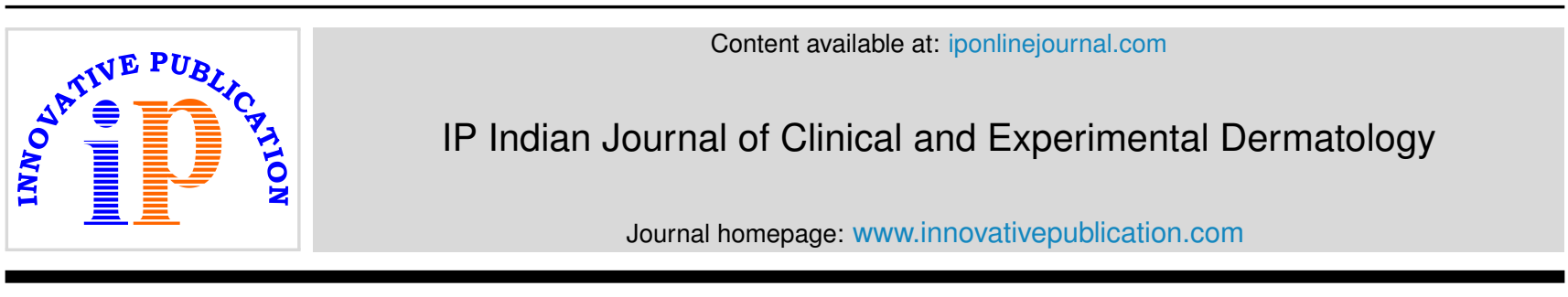

Original Research Article

\title{
Clinico -laboratory and trichoscopic evaluation of various patterns of female baldness - A prospective case control study
}

\author{
Sappa Ramatulasi ${ }^{1}$, Manjari Annapurna Malladi ${ }^{1 * *}$, Ruttala Sri Satya ${ }^{1}$, Kashetty Srujan \\ Kumar', Anand Acharya ${ }^{2}$ \\ ${ }^{1}$ Dermatology Venereology leprosy, KIMS, Amalapuram, Andhra Pradesh, India \\ ${ }^{2}$ Pharmacology, KIMS, Amalapuram, Andhra Pradesh, India
}

\section{A R T I C L E I N F O}

Article history:

Received 24-06-2019

Accepted 31-07-2019

Available online 14-09-2019

Keywords:

Trichoscopic features

Patterns of female Baldness

Case control study

\begin{abstract}
A B S T R A C T
Introduction: Female pattern hair loss (FPHL) is a form of non scarring diffuse hair loss and hair thinning in a pattern fashion. The role of hyperandrogenemia is not clear in FPHL. An association between iron deficiency and FPHL is also debated. Literature investigating trichoscopic features in this condition are few.

Aim : To analyse the clinico laboratory findings in women with pattern baldness and to correlate the trichoscopic parameters in the three forms of FPHL namely Ludwig, Olsen, Hamilton \& Norwood.

Materials and Methods : This was a prospective case control study. Seventy (70) female patients of age between 18-48 years with pattern baldness and thirty(30) age matched females were included in the study. Trichoscopy was done for all the cases. Laboratory evaluation was done for both cases and controls. The data was analysed using SPSS 16.0 version. Chi Square and ' $t$ ' tests were used and the results expressed in mean, standard deviation.

Results: A statistically significantly difference was observed between the mean values of total testosterone, DHEAS, TSH of cases when compared to controls. The serum ferritin level less than the cut off level of $40 \mathrm{mic}$.gram/L was seen in $52 \%$ of cases and the mea $\mathrm{n}$ serum ferritin values of cases is less than that of controls. Hair diameter diversity ( $90 \%)$, peripilar sign $(91.4 \%)$ were the most frequent trichoscopic findings. Conclusion: The biochemical findings in our study support the role of hormones, Iron deficiency in the etiology of FPHL. The trichoscopic findings did not differ significantly between the three forms of FPHL.
\end{abstract}

(C) 2019 Published by Innovative Publication.

\section{Introduction}

Hair loss can potentially result in low self- esteem and poor body imge especially in women. Female pattern hair loss (FPHL) is a form of non scarring diffuse hair loss and hair thinning in a pattern fashion and can affect women as early as in their teen years. ${ }^{1}$ Genetic predisposition \& hormonal abnormalities like hyperandrogenism, hair cycle defects and follicular miniaturization have been implicated as etiopathogenetic factors for androgenic alopecia. There is a difference in the pathogenesis of patterned baldness in men and women. The role of hyperandrogenemia is not very clear in FPHL. ${ }^{2}$ An association between iron deficiency and

\footnotetext{
* Corresponding author.

E-mail address: manjari7malladi@gmail.com (M. Annapurna Malladi).
}

FPHL is also debated. Trichoscopy as a tool for evaluating hair loss disorders had gained momentum for the past one decade. However, studies investigating the features of patterned hair loss in females are few. This study was aimed to analyse the clinico- laboratory findings in women with pattern hair loss and to correlate the trichoscopic parameters in the three form $s$ of female pattern hair loss namely Ludwig, Olsen, Hamilton \& Norwood.

\section{Materials and methods}

\subsection{Cases}

Seventy female (70) patients of age between 18 to 48 years with history of hair loss over the scalp with the clinical features of pattern hair loss like thinning of hair over the 
crown, temporal area, recession of hair line, widening of central partition were included in the study after taking informed consent. The study has been approved by the institutional ethics committee.

\subsection{Exclusion Criteria}

Pregnant women, lactating mothers, postmenopausal or hysterectomised patients were excluded.

Patients with known endocrine disorders or those who are on hormonal therapies like oral contraceptive pills were excluded.

Patients on oral or topical treatments for hair loss were not included in the study.

Patients on drugs causing hair loss such as steroids, immunosuppressives, retinoids, anti cancer drugs were also excluded.

Patients with other types of cicatricial, non cicatricial alopecia and any hair shaft disorders were excluded

\subsection{Controls}

Thirty (30) female patients of age between 18 to 48 years with no clinical signs of hair loss or hyperandrogenism were included in the control group after taking informed consent.

History was obtained from each patient using a standard proforma which included age, marital status, parity, age of onset of hair loss, duration, menstrual irregularities.

Cutaneous examination was done to look for signs of hyperandrogenism like acne, hirsutism, acanthosis nigricans, striae. Scalp and hair were examined to rule out any signs of inflammation or scarring or any hair shaft abnormalities. The extent and pattern of hair loss was assessed by the severity of hair loss on the crown, recession of frontal hair line, involvement of fronto- temporal area and the patient $\mathrm{s}$ were then classified i $\mathrm{n}$ to Ludwig, ${ }^{3}$ Olsen, ${ }^{4}$ Hamilton \& Norwood ${ }^{5}$ types.

Trichoscopy was done using Dermaindia Wifi 2.0 dermoscope. Frontal, temporal, vertex, occipital areas were observed and images captured with the help of iphone 6 for analysis. Image capturing was performed by a single person to avoid variation. Morning blood sample was collected for hormonal and biochemical analysis on $3^{\text {rd }}$ to $5^{\text {th }}$ day of the menstrual cycle from the patients with regular cycles or on any other day from the patient who haven't menstruated in the past 2 months.

Total testosterone, dehydroepiandrosterone acetate(DHEAS), LH / FSH, prolactin, T3, T4, TSH, serum ferritin were done.

Ultrasound pelvis was done between $3^{\text {rd }}$ and $5^{\text {th }}$ day of menstrual cycle. A diagnosis of PCOS was done based on modified National I nstitute of Health (NIH) criteria. ${ }^{6}$

The data was tabulated in excel sheets and analysed using SPSS 16.0 version. The parametric data was analysed by unpaired ' $t$ ' test and non parametric data by Chi Square test.
$\mathrm{P}$ value $<0.05$ was considered statistically significant. The results were expressed in mean, standard deviation.

\section{Results}

Out of the 70 patients, majority $42(60 \%$ ) were in 29 t o 38 year age group followed by $15(21.43 \%)$ in 18 to 28 year age group and 13(18.57\%) in 39 to 48year age group (Table 1 ). $\mathrm{T}$ he mean age at presentation was 33 years $(\mathrm{sd} \pm 4.5)$. The mean age of control group was 31.7 years ( $\mathrm{sd} \pm 3.2$ ).

The mean age of onset of hair fall was $26.6(\mathrm{sd} \pm 2.4)$ years and the mean duration of hair loss was $4.8(\mathrm{sd} \pm 1.8)$ years. In more than half of the patients, $(53 \%)$ the duration of hair fall was 2 to 4 years where as it was less than 2 years in $30 \%$ of patients and the rest $17 \%$ of patients had hair loss for more than 4 years.

Family history of pattern hair loss was positive in $56 \%$ of patients. After detailed examination of scalp, t he patients were classified in to the three patterns of FPHL (Table 2 ).

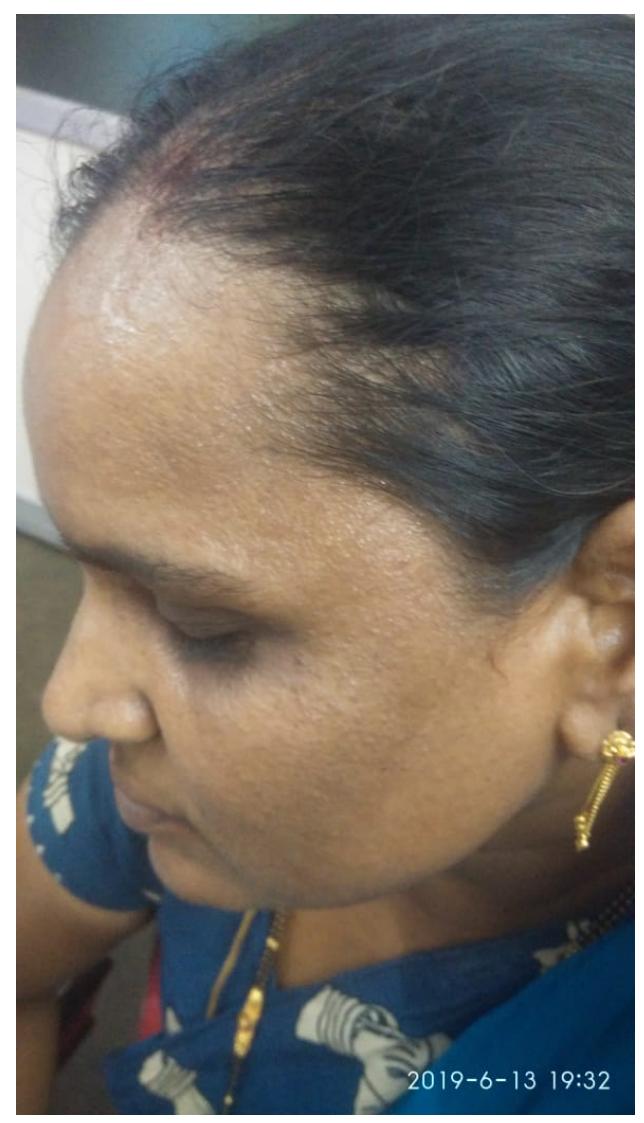

Fig. 1: Hamilton \& Norwood pattern

PCOS was diagnosed by modified NIH criteria in 19 patients $(27.14 \%)$ of the total cases.

The parameters observed on trichoscopy were (Figures 1, 2, 3, 4 and 5 ) 
Table 1: Age distribution of cases and controls

\begin{tabular}{lll}
\hline Age in years & Cases $(n=70)$ & Controls $(\mathbf{n = 3 0})$ \\
$18-28$ & $15(31.43 \%)$ & $6(20 \%)$ \\
$29-38$ & $42(60 \%)$ & $16(53.3 \%)$ \\
$39-48$ & $13(18.57 \%)$ & $8(26.66 \%)$ \\
\hline
\end{tabular}

Table 2: classification of patients according to Pattern of hair loss and Assosciated cutaneous findings

\begin{tabular}{|c|c|c|c|}
\hline \multirow[t]{2}{*}{ Variables } & & Number & Percentage \\
\hline & Ludwing & $48 / 70$ & $68.5 \%$ \\
\hline \multirow[t]{3}{*}{ Pattern of hairloss } & Olseci & $18 / 70$ & $25.8 \%$ \\
\hline & Hamilton and Narwood & $4 / 70$ & $5.7 \%$ \\
\hline & Acne & $20 / 70$ & $28.5 \%$ \\
\hline \multirow[t]{2}{*}{ Cutaneous findings } & Acanthosis nigracans & $26 / 70$ & $37 \%$ \\
\hline & Hirsutism & $28 / 70$ & $40 \%$ \\
\hline
\end{tabular}

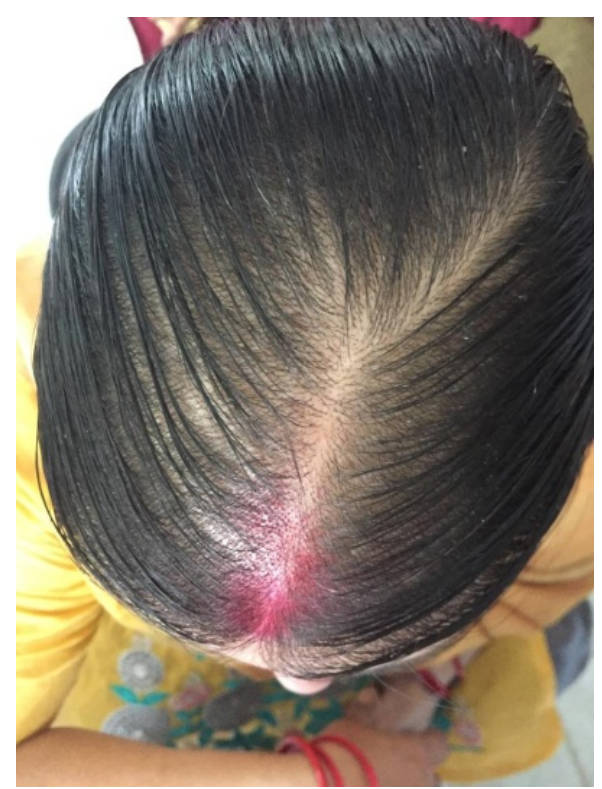

Fig. 2: Olsen pattern

1. Hair diameter diversity (HDD): corresponds to vellus hair transformation

2. Brown peripilar sign (BPPS): subtle brown halo around the hair shaft

3. White peripilar sign (WPPS): larger in size as white halo at the follicular ostium

4. Yellow dots (YD) are are follicular infundibula with keratotic material and/or sebum

5. Focal atrichia: They are areas of total hair loss on scalp, usually in a size of a pencil eraser

6. Scalp honeycomb pigmentation (SHCP ): which correspon ds to melanotic rete ridges

7. Single follicular unit(SFU)

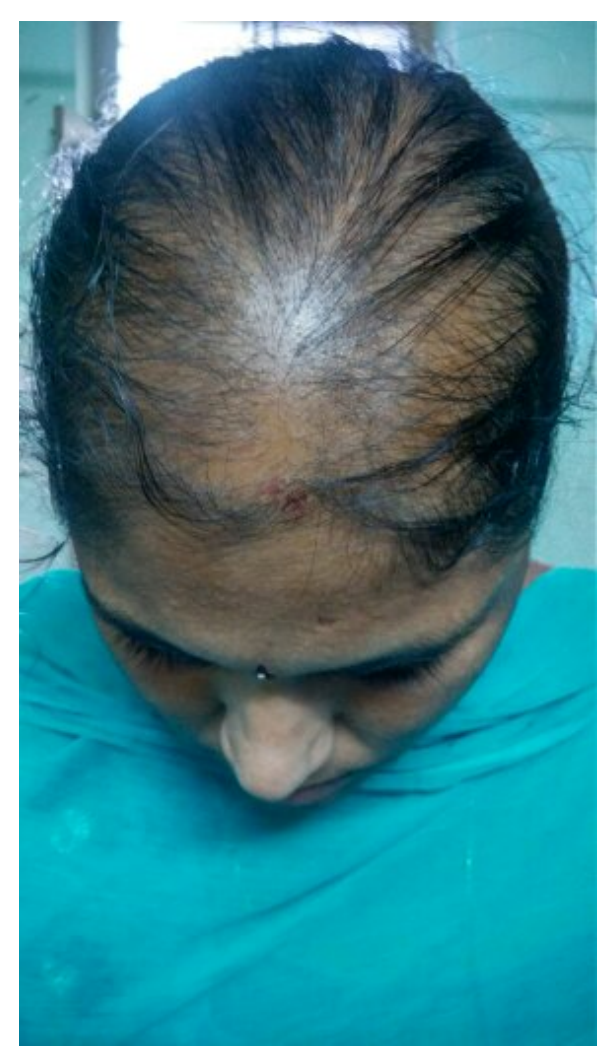

Fig. 3: Ludwig pattern

\section{Discussion}

In this study, majority of the patients(60\%) were in the age group of $29-38$ years similar to the study done in Tandon $\mathrm{S}$ et $\mathrm{al}^{2}$ where in more than half of the patients were in 28-37 year age group. Similar observations were made by Lee et $\mathrm{al}^{7}$ in their study of 445 patients out of which $252(56.68 \%)$ were in the third decade of their life. The mean age of presentation in the present study was 33 years ( $\mathrm{sd} \pm 4.5$ ). It was 37 years in a recent study by Ummita A et $\mathrm{al}^{8}$ while it was 35.8 years in $\mathrm{Hu}$ et $\mathrm{al}^{9}$ study done on 
Table 3: Trichoscopic findings

\begin{tabular}{lllll}
\hline Total no. of cases $(\mathbf{n}=\mathbf{7 0})$ & Ludwig $(\mathbf{n}=\mathbf{4 8})$ & Olsen $(\mathbf{n}=\mathbf{1 8})$ & Hamilton \&Norwood $(\mathbf{n}=4)$ & 'P' value \\
Yellow dots (40) & $27(56.21)$ & $10(55 \%)$ & $3(75 \%)$ & $0.82(>0.05)$ \\
BPPS (33) & $23(48 \%)$ & $8(44.4)$ & $2(50 \%)$ & $0.96(>0.05)$ \\
WPPS (31) & $20(41.6 \%)$ & $9(50 \%)$ & $2(50 \%)$ & $0.51(>0.05)$ \\
HDD (63) & $43(90 \%)$ & $16(89.5 \%)$ & $4(100 \%)$ & $0.79(>0.05)$ \\
SFU (56) & $37(77 \%)$ & $16(88 \%)$ & $3(75 \%)$ & $0.56(>0.05)$ \\
WD (29) & $19(39.5 \%)$ & $9(50 \%)$ & $1(25 \%)$ & $0.64(>0.05)$ \\
Scalp pigmentation(42) & $29(63 \%)$ & $11(66 \%)$ & $2(50 \%)$ & $0.91(>0.05)$ \\
Focal atrichia (11) & $7(14.5)$ & $3(16.6 \%)$ & $1(25 \%)$ & $0.97(>0.05)$ \\
\hline
\end{tabular}

Table 4: Laboratory findings

\begin{tabular}{lllll}
\hline HORMONE & Units & Cases Mean \pm sd & Controls Mean \pm sd & P VALUE \\
Total testosterone & ng/dl & $52.7 \pm 19.75$ & $35.2 \pm 12.36$ & $<0.05 \#$ \\
DHEAS & mic.gm/dl & $179 \pm 61.27$ & $154.56 \pm 52.14$ & $<0.05 \#$ \\
T3 & ng/dl & $121.52 \pm 48.07$ & $123.56 \pm 36.04$ & $>0.05$ \\
T4 & mic.gm/dl & $7.9 \pm 2.72$ & $7.72 \pm 1.98$ & $>0.05$ \\
TSH & Micro IU/ml & $6.87 \pm 1$ & $3.17 \pm 1.97$ & $<0.05 \#$ \\
LH/FSH ratio & & $0.8 \pm 0.32$ & $0.75 \pm 0.58$ & $>0.05$ \\
PROLACTIN & ng/lit & $16.95 \pm 6.22$ & $14.53 \pm 7.26$ & $>0.05$ \\
S.FERRITIN & microgm/lit & $43.74 \pm 25.77$ & $51.03 \pm 29.2$ & $>0.05$ \\
\hline
\end{tabular}

\# statistically significant



Fig. 4: HDD

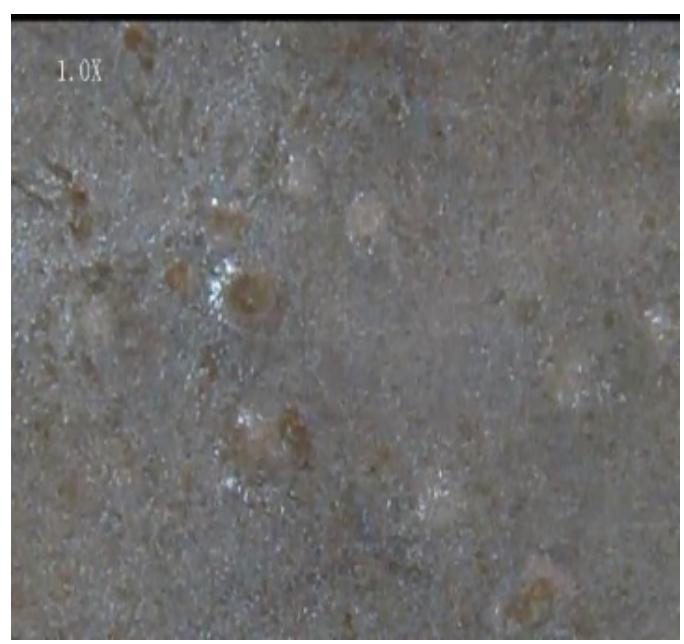

Fig. 5: YD \& WD

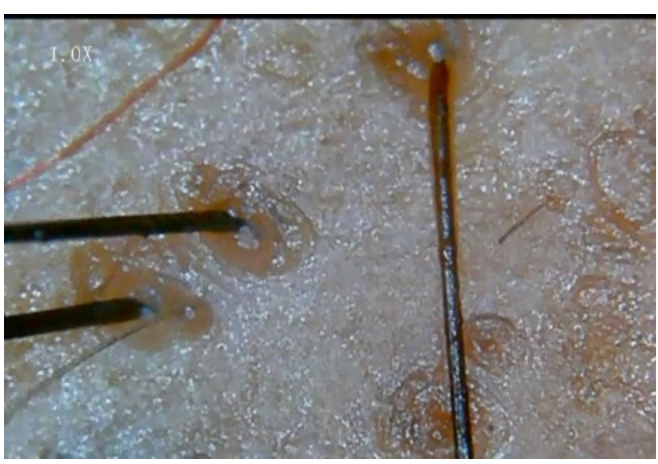

Fig. 6: BPPS

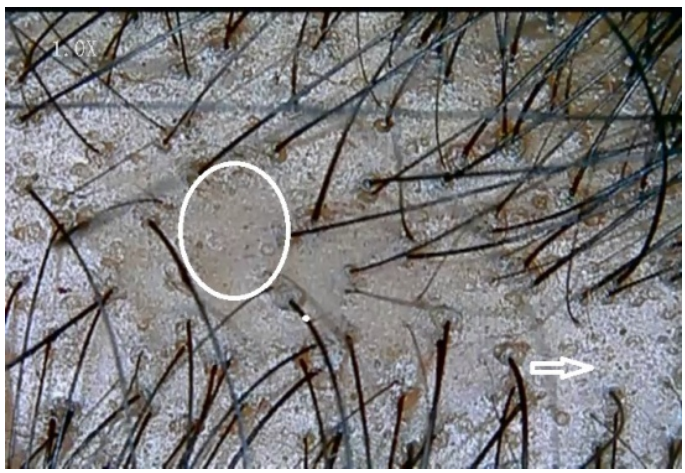

Fig. 7: F ocal atrichia \& SHCP 


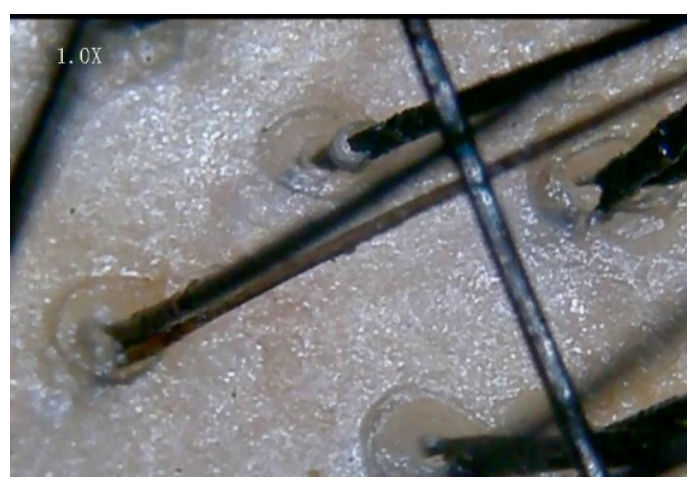

Fig. 8: WPPS

\section{Chinese population.}

The mean age of onset of hair fall was 26.6( $\mathrm{sd} \pm 2.4) \mathrm{y}$ ears in our study which is nearer to the study $b$ y Tandon $S$ et $\mathrm{al}^{2}$ (26.1 years). In a study conducted by Shilpashree et al ${ }^{10}$ mean age of onset was $28.4 \pm 8.2$ years which is very similar to our study. Norwood ${ }^{11}$ reported that Caucasian women had FPHL which begins in late 20s which is in accordance with this study. The mean age of onset was little high (29.8 years)in a study by Zhang et $\mathrm{al}^{1}$ on Chinese women and it was little less ( 23 years) in the study done by Kasick et al ${ }^{12}$

The mean duration of hair fall was 4.8 years $(\mathrm{sd} \pm 1.8)$ in the present study which is well in agreement with the studies of Zhang et $\mathrm{al}^{1}$ and Tandon $\mathrm{S}$ et $\mathrm{al}^{2}$ where the mean duration was 5.1 years and 4.49 years respectively.

Family history of hair loss was noticed in $56 \%$ of our patients which is similar to the study conducted by Shilpashree et al ${ }^{10}$ at $51 \%$. It varied from 19.2 to $32.4 \%$ in various Chinese studies. ${ }^{1113}$ The incidence of family history of baldness was $45.2 \%$ in the study by Paik et al ${ }^{14}$ on Korean women and $45 \%$ in the study by Zhang et $\mathrm{al}^{1}$ on Chinese women which are in near agreement with our study. In the study by Tee Wei Siah et $\mathrm{al}^{15} 85 \%$ of patients had family history of baldness.

The cutaneous findings of hyperandrogenism observed in assosciation with FPHL in our patients were Hirsutism (40\%), Acanthosis nigracans (37\%) and acne (28.5\%)

Most of the previous studies reported hirsutism in 12$22 \%$ of patients. ${ }^{16-18}$ where as Tandon $\mathrm{S}$ et $\mathrm{al}^{2}$ reported hirsutism in $66.6 \%$ of their patients.

Cela et al ${ }^{16}$ reported acne in 38 of 80 patients $(43 \%)$ and Moltz ${ }^{17}$ and Tandon $\mathrm{S}$ et $\mathrm{al}^{2}$ observed acne in $41.6 \%$ and $36.6 \%$ of their patients respectively.

$43.3 \%$ of patients with FPHL had acanthosis nigracans in the study by Tandon $\mathrm{S}$ et $\mathrm{al}^{2}$ which is little higher than that observed in our study $(37 \%)$.

P COS was diagnosed based on modified NIH criteria in 19 of the total 70 patients $(27.14 \%)$. Cela et al $^{16}$ at the reproductive endocrinology service in London reported a higher prevalence of PCOS (67)\% while Quinn et al ${ }^{19}$ and $^{2}$ Tandon $S$ et $\mathrm{al}^{2}$ reported $22 \%$ and $26.6 \%$ respectively which is similar to the present study. This difference in the prevalence could be due to different population groups studied, difference in sample size and screening methods used in diagnosis.

Various studies have evaluated the role of hyperandrogenemia in FPHL but the results were discordant. Molly Quinn et al ${ }^{19}$ did not find a difference in overall biochemical hyperandrogenemia between subjects with and without AGA. Similarly, Ozdemir et al ${ }^{20}$ concluded that AGA was not a marker for hyperandrogenemia. In contrast, Cela et $\mathrm{al}^{16}$ reported a higher total testosterone, androstenedione and free testosterone index in 89 women with AGA compared with 73 control women.

In the present study, the difference between the mean values of total testosterone, DHEAS and TSH of cases were statistically significant when compared with that of controls (Z-test $\mathrm{p}<0.05)$ which is similar to the observations made by Tandon et al. ${ }^{2}$ Kasick et al ${ }^{12}$ also reported a significant increase in DHEAS levels in cases compared to controls. However, total serum testosterone levels were normal in all their subjects whereas $19 \%$ of our patients had serum total testosterone above the normal range.

DHEAS, apart from conversion to potent androgens, has a direct action on hair follicle as inhibitor of G6PD (glucose 6 phosphate dehydrogenase) there by inhibiting nucleic acid synthesis. This suggests that the se low potent adrenal androgens are sufficient to cause FPHL with or without other findings of hyperandrogenism. However, Montalto et $\mathrm{al}^{21}$ and Rushton et al ${ }^{18}$ did not find a significant increase in the plasma levels of DHEAS in their studies.

TSH and prolactin can interact with androgen metabolism at various levels. Futterweit et $\mathrm{al}^{22}$ reported that two patients had hyperprolactinemia out of the 109 female patients with diffuse alopecia. Schimdt et $\mathrm{al}^{23}$ had studied hypoth yroidism and hyperprolactinemia as a possible cause of androgenetic alopecia in females and found that $23 \%$ of their patients had raised TSH which is in accordance with our study where $28.5 \%$ patients had raised TSH levels. One third of (29\%) their patients had raised prolactin. In contrast, all our patients had normal prolactin levels.

The relationship between serum ferritin and hair loss has been investigated in a number of studies however with relatively discrepant findings. Sinclair $^{24}$ in his study found no direct relationship between low serum ferritin and hairloss. Rasheed et $\mathrm{al}^{25}$ found that serum ferritin levels in TE and FPHL cases were significantly lower than in controls. There is a wide range of serum ferritin level (6$160 \mathrm{mic} . \mathrm{gm} / \mathrm{l}$ ). However, as per the literature a cut off of 41 mic.gm/l yields specificity of $98 \%$ and sensitivity of $98 \%$. When this cut off level was taken, more than half $(52 \%)$ of our patients fall under this group which is comparable to Olsen et $\mathrm{al}^{26}(58.8 \%)$ and Rushton et al ${ }^{18}$ studies( $65 \%$ ) indicating an association between Iron deficiency and 
FPHL. In our study, the mean serum ferritin level of patients were less than that of controls but this was not statistically significant.

The patients were classified in to three patterns of hair loss (Table 2 ) and the trichoscopic findings in each pattern were as shown in Table 4 .

Hair shaft diameter diversity (HDD) was established by Rakowska et al ${ }^{27}$ as one of the major criteria of FPHL. It was observed in $93 \%$ of our patients similar to the study done by Galliker and Treub et $\mathrm{al}^{28}$ where HDD was seen in $72 \%$ of early and $100 \%$ of advanced female androgenetic alopecia patients.

Brown peripilar sign (BPPS) was seen in $47 \%$ of our patients similar to Ummiti $\mathrm{A}$ et $\mathrm{al}^{8} 40 \%$ and $\mathrm{Hu}$ et $\mathrm{al}^{9}$ $(44.5 \%)$ studies. It was $31.7 \%$ in a Chinese study by Zhang et al. ${ }^{1}$ In contrast, Deloche et al ${ }^{29}$ reported it to be $86 \%$ in caucasian women with FPHL and Inuis et $\mathrm{al}^{30}$ detected this finding in $20 \%$.

White peripilar sign ( WPPS) was noticed in $44.2 \%$ of patients in the present study. Its incidence varied from 15 to $68 \%$ in various studies ${ }^{1,8,9}$

Yellow dots(YD) were seen in 40 out of 70 pts (57\%) in our study. Contrastingly its incidence was high $(88 \%)$ in Ummiti A et al ${ }^{8}$ and very low in Zhang et al ${ }^{1}$ study $(1.67 \%)$. $\mathrm{Hu}$ et $\mathrm{al}^{9}$ observed this finding in $24 \%$ of FAGA patients. This disparity of findings can be due to different skin phenotypes with variation in sebaceous gland activity as well as degree of pigmentation of scalp as suggested by Ummiti A et al. ${ }^{8}$

Focal atrichia referred to as pencil erased focal loss of hair was found in $18.6 \%$ in our study nearer to that observed by Ummiti A et al ${ }^{5}$ (24\%) whereas Hu et $\mathrm{al}^{9}$ \& $\mathrm{Zhang}$ et $\mathrm{al}^{1}$ reported its incidence in more than half of their patients. Zhang et al ${ }^{1}$ correlated this finding with advancing stage $o$ $\mathrm{f}$ androgenic alopecia.

Scalp honey comb pigmentation was observed in $60 \%$ patients similar to Zhang et al ${ }^{1}(61.7 \%)$ study where as in a chinese study by $\mathrm{Hu}$ et $\mathrm{al}^{9}$ it was seen in $30.5 \%$ and in Ummiti A et $\mathrm{al}^{8}$ study it was seen in $80 \%$ of patients.

In addition to these, we observed white dots (representing empty follicles) in $41.4 \%$ of patients and single follicular units in $80 \%$ of patients. To the best of our knowledge, there are no previous studies comparing the trichoscopic findings in various forms of female baldness. As per our study, there is no stastically significant difference in the incidence of parameters of trichoscopy among the three patterns of hair loss.

\section{Funding}

None.

\section{Conflict of Interest}

None.

\section{References}

1. Zhang X, Caulloo S, Zhao Y, Zhang B, Cai Z, Yang J. Female pattern hair loss: clinico-laboratory findings and trichoscopy depending on disease severity. Int J Trichology. 2012;4:23-31.

2. Tandon S, Arora P, Gautam RK, Bhardwaj M, Garga U, Sharma N ; with patterned baldness.

3. Ludwig E. Classification of the types of androgenetic alopecia (common baldness) occurring in the female sex. $\mathrm{Br} J$ Dermatol. 1977;97:247-54

4. Olsen EA. Androgenetic alopecia. In: Disorders of hair growth: diagnosis and treatment. McGrawHill ; 1994,. p. 257-283.

5. Norwood OT. Male pattern baldness:classification and incidence. South Med J. 1975;68:1359-65.

6. Azziz R. Diagnostic criteria for polycystic ovary syndrome: a reappraisal. FertilSteril. 2005;83:1343-1349.

7. Lee WS, Ro BI, Hong SP, Bak H, Sim WY, Kim DW. A new classification of pattern hair loss that is universal for men and women: basic and specific (BASP) classification. J Am AcadDermatol. 2007;57:37-46

8. Ummiti A, Ps P, Chandravathi PL, Kumar CS. Correlation of trichoscopic findings in androgenic alopecia and the disease severity. Int J Trichol. 2019;11:118-140.

9. Hu R, Xu F, Han Y, Sheng Y, Qi S, Miao Y. Trichoscopic findings of androgenetic alopecia and their association with disease severity. $J$ Dermatol. 2015;42:602-609.

10. Shilpashree P, Ravikiran. An epidemiological study of female pattern hair loss at a referral centre in South India Indian. Journal of Clinical and Experimental Dermatology. 2016;2(3):106-110.

11. 11 Norwood OT. Incidence of female androgenetic alopecia (female pattern alopecia). DermatolSurg. 2001;27:53-57.

12. Kasick JM, Bergfeld WF, Steck WD, Gupta MK. Adrenal androgenic female-pattern alopecia: sex hormones and the balding woman. Cleve Clin Q. 1983;50:111-133.

13. Gonzalez ME, Cantatore-Francis J, Orlow SJ. Androgenetic alopecia in the paediatric population: A retrospective review of 57 patients. $\mathrm{Br}$ J Dermatol. 2010;163(10):378-85.

14. Paik JH, Yoon JB, Sim WY, Kim BS, Kim NI. The prevalence and types of androgenetic alopecia in Korean men and women. $\mathrm{Br} \mathrm{J}$ Dermatol. 2001;145:95-104.

15. Jerry Shapiro Female Pattern Hair Loss: A Retrospective Study in a Tertiary Referral Center. Int J Trichology. 2016;8(2):57-61.

16. Cela E, Robertson C, Rush K, Kousta E, White DM, et al. Prevalence of polycystic ovaries in women with androgenic alopecia. Eur $J$ Endocrinol. 2003;149:439-442.

17. 17 Moltz L. [Hormonal diagnosis in so-called androgenetic alopecia in the female. GeburtshilfeFrauenheilkd. 1988;48:203-217.

18. Rushton DH, Ramsay ID, James KC, Norris MJ, Gilkes JJ. Biochemical and trichological characterization of diffuse alopecia in women. Br J Dermatol. 1990;123:187-97.

19. Quinn M, Shinkai K, Pasch L, Kuzmich L, Cedars M, Huddleston H. Prevalence of androgenic alopecia in patients with polycystic ovary syndrome and characterization of associated clinical and biochemical features. FertilSteril. 2014;101:1129-1163.

20. Ozdemir S, Gorkemli M, Kiyici H, Bodur A, S. Specific dermatologic features of the polycystic ovary syndrome and its association with biochemical markers of the metabolic syndrome and hyperandrogenism. ActaObstetGynecol Scand. 2010;89:199-204.

21. Montalto J, Whorwood CB, Funder JW, Yong AB, Callan A, Davies HE. Plasma C19 steroid sulphate levels and indices of androgen bioavailability in female pattern androgenic alopecia. ClinEndocrinol (Oxf). 1990;32:1-12.

22. Futterweit W, Dunaif A, Yeh HC, Kingsley P. The prevalence of hyperandrogenism in 109 consecutive female patients with diffuse alopecia. J Am AcadDermatol. 1988;19:831-837.

23. Schmidt JB, Schurz B, Huber J, Spona J. Hypothyroidism and hyperprolactinemia as a possible cause of androgenetic alopecia in the female. Z Hautkr. 1989;64:9-12. 
24. Sinclair R. There is no clear association between low serum ferritin and chronic diffuse telogen hair loss. Br J Dermatol. 2002;147:982986.

25. Rasheed H, Mahgoub D, Hegazy R, El-Komy M, Hay A, et al. Serum ferritin and Vitamin D in female hair loss: Do they play a role? Skin PharmacolPhysiol. 2013;26:101-108.

26. Olsen EA, Reed KB, Cacchio PB, Caudill L. Iron deficiency in female pattern hair loss, chronic telogen effluvium, and control groups. $J$ Am AcadDermatol. 2010;63:991-1000.

27. Rakowska A, Slowinska M, Kowalska-Oledzka E, Olszewska M, Rudnicka L. Dermoscopy in female androgenic alopecia: Method standardization and diagnostic criteria. Int J Trichology. 2009;1:123153.

28. Galliker NA, Treb RM. Value of trichoscopy versus trichogram for diagnosis of female androgenetic alopecia. Int $J$ Trichology. 2012;4:19-22.

29. Deloche C, Lacharrire OD, Misciali C, Piraccini BM, Vincenzi C, Bastien P. Histological features of peripilar signs associated with androgenetic alopecia. Arch Dermatol Res. 2004;29:422-430.

\section{Author biography}

Sappa Ramatulasi Assistant Professor

Manjari Annapurna Malladi Senior Resident

Ruttala Sri Satya Post Graduates

Kashetty Srujan Kumar Post Graduates

Anand Acharya Professor and Head

Cite this article: Ramatulasi S, Annapurna Malladi M, Sri Satya R, Srujan Kumar K, Acharya A. Clinico -laboratory and trichoscopic evaluation of various patterns of female baldness - A prospective case control study. Indian J Clin Exp Dermatol 2019;5(3):195-201. 